\title{
Museologia Social e novos atores no Rio de Janeiro: o caso do Museu de Favela
}

\author{
LEONARDO PERDIGÃO LEITE \\ Universidade do Estado do Rio de Janeiro, Rio de Janeiro, Brasil \\ DOI 10.11606/issn.2316-9133.v28i1p273-294
}

resumo $O$ presente trabalho visa tecer relações entre as novas produções museais e museológicas presentes na cidade do Rio de Janeiro com discussões sobre patrimônios, memórias e museus. O estudo foi pautado na corrente teórica conhecida como Museologia Social ou Sociomuseologia. Também são analisadas as mudanças paradigmáticas que essa maneira de pensar e fazer museus traz para a área. Ademais, discutimos alguns projetos museais inovadores pautados nesses princípios, como o Museu de Favela Cantagalo PavãoPavãozinho (MUF), e como a entrada de novos atores nas discussões sobre os patrimônios, os museus e as memórias abre a área para novos modos de pensar, fazer e conceituar esses campos, mostrando que há sempre uma disputa política e de poder nesses movimentos. A pesquisa mescla o trabalho de campo no MUF e a revisão bibliográfica sobre o tema.

palavras-Chave Museologia Social; Museu de Favela; Patrimônio; Memória; Poder.

Sociomuseology and new actors in Rio de Janeiro: the case of Favela Museum

abstract The article tries to stablish relations between new museal and museologic productions present in the city of Rio de Janeiro with discussions about heritage, memory and museums. The study was based in the theorical research known as sociomuseology. We also analyse how this research bring paradigmatic changes to the area. Furthermore, we discuss some innovative actions based on sociomuseology principles such as the Favela Museum Cantagalo Pavão-Pavãozinho (MUF), and how the arrival of new actors in the debate about heritage, museums and memories open the area to new modes of thinking, doing and conceptualize this fields of knowledge, showing that there is always power and political disputes in this areas.

Keywords Sociomuseology; Favela Museum; Heritage; Memory; Power. 


\section{Considerações iniciais}

O presente trabalho ${ }^{1}$ visa tecer relações entre as novas produções museais presentes na cidade do Rio de Janeiro com discussões sobre patrimônio e museus. Desta forma, nos pautamos na área da Museologia Social e das mudanças paradigmáticas que essa maneira de pensar e fazer museus traz para a área. Ademais, discutimos alguns projetos museais inovadores como o Museu de Favela Cantagalo Pavão-Pavãozinho (MUF) e a entrada de novos atores nas discussões sobre o patrimônio, os museus e sobre o campo da memória. $\mathrm{O}$ artigo é um desdobramento dos estudos realizados por mim no doutorado e mescla a revisão bibliográfica com trabalhos de campo realizados no MUF no ano de 2017.

O histórico das mudanças no campo dos museus começa nos idos de 1960 com a percepção de que muitas instituições haviam se enrijecido demais em suas práticas e adotavam os modelos coloniais europeus como a única forma de atuar. Muitos trabalhadores, pesquisadores e gestores de museus achavam que esta não era a melhor maneira de desenvolver seus trabalhos e começaram a desenvolver práticas que tentavam se distanciar do modelo tradicional. Também é preciso apontar que os movimentos sociais que questionavam outras instituições como escolas e teatros, focam igualmente os museus e seu elitismo. A partir dos anos 1980 e 1990 vemos que o conceito da Nova Museologia se expandiu mundo afora e teve grande influência nos modelos museais que passaram a ser constituídos no Brasil.

Chegamos ao século XXI e vemos que novas formas de fazer e pensar museus pulsa na área. Também vemos novos atores, que partem de referências práticas para pensar a teoria, disputar com o modo tradicional de fazer, que pensa de cima pra baixo e que coloca em caixas fechadas e isoladas o modo pelo qual os museus devem agir e como devem se comportar.

Chagas et all (2018) ressaltam que as memórias, os patrimônios e os museus são bons para agir, pensar e sentir. Mas que eles são territórios inseguros, campos de luta, de conflito e disputa. E disputa-se o passado, o presente e o futuro; o lugar, o espaço e o território; a liberdade, a criatividade e o discurso.

Desta forma, desenvolvemos ao longo do texto as conceituações e contribuições da Museologia Social para área, analisamos a experiência do Museu de Favela e discutimos como a entrada de novos atores e novos modos de fazer afetam os debates teóricos sobre os patrimônios, as memórias e os museus.

\section{Sobre a Museologia Social}

\footnotetext{
${ }^{1}$ Esta pesquisa foi realizada com apoio da Fundação Carlos Chagas de Apoio à Pesquisa do Rio de Janeiro (FAPERJ).
} 
O termo Museologia Social ou Sociomuseologia foi cunhado em 1993. Para chegar ao termo os pensadores partem de discussões prévias organizadas em eventos da área museológica como a Mesa Redonda de Santiago do Chile em 1972 e da Declaração de Quebec em 1984. Notava-se, desde a década de 1960, a necessidade da atualização dos museus e de sua adaptação e adequação às mudanças sociais, econômicas e tecnológicas das sociedades contemporâneas.

As principais características dessa corrente teórica são: o alargamento da noção de patrimônio; a redefinição do objeto museológico; a participação e inclusão das comunidades na definição e gestão de práticas museológicas e de instituições museais; o uso da museologia como fator de desenvolvimento; a interdisciplinaridade do mundo dos museus; e o uso de novas tecnologias de informação e comunicação. (MOUTINHO, 1993).

Chagas e Gouveia (2014) apontam que as revoluções dos jovens nos anos de 1960, insatisfeitos com o sistema e as guerras ao redor do mundo e a criação de novos modos de vida e novas formas de comportamento também impactaram o mundo dos museus. Os autores também ressaltam que uma entrevista de Hughes de Varine em 1979, teórico francês da museologia, pode ser considerada um documento de referência da área. $\mathrm{Na}$ entrevista Varine ressalta que os modelos museal e museológico ${ }^{2}$ do continente Europeu foram impostos aos países em desenvolvimento através de processos coloniais e que apesar da libertação política, a área cultural ainda continuou sob a mentalidade colonizada.

A entrevista, publicada em três línguas, teve forte impacto em Portugal, México, Brasil e Canadá que já tinham experiências museológicas que se distanciavam do modelo tradicional europeu. Podemos notar que "o referido diagnóstico ao denunciar a colonização dos museus, provocava e estimulava naqueles que tinham capacidade de agir e pensar por outras veredas a vontade de investir na descolonização do museu e do pensamento museológico" (CHAGAS; GOUVEIA, 2014, p.10).

A Mesa Redonda de Santiago tem como grande contribuição para a área da museologia a noção de Museu Integral que consiste em uma nova tomada de posição por parte das instituições museais no que tange a sua integração à vida da sociedade estando atentas as transformações sociais, econômicas e culturais.

Esta nova visão não deveria se sobrepor ou suprimir outros modelos de instituições museais, deixando claro que até os museus tradicionais poderiam trabalhar na perspectiva do Museu Integral mantendo uma visão de conjunto do meio material e cultural das sociedades. Ademais, insere-se, mais abertamente, no mundo dos museus a ideia de interdisciplinaridade em contraponto a ideia de que uma disciplina poderia dar conta dos múltiplos aspectos da realidade. No documento encontramos a seguinte definição de museu, que:

é uma instituição a serviço da sociedade, da qual é parte integrante e que possui nele mesmo os elementos que lhe permitem participar na

\footnotetext{
${ }^{2} \mathrm{O}$ termo museal se refere aos museus, enquanto museológico se refere à Museologia.
} 
formação da consciência das comunidades que ele serve; que ele pode contribuir para o engajamento destas comunidades na ação, situando suas atividades em um quadro histórico que permita esclarecer os problemas atuais, isto é, ligando o passado ao presente, engajando-se nas mudanças de estrutura em curso e provocando outras mudanças no interior de suas respectivas realidades nacionais. (UNESCO, 1972).

Apesar do caráter social e da posição ativa dos museus propostas na Mesa Redonda, houve pouca mudança efetiva no panorama dos museus brasileiros. Muito se deve a ditadura militar e ao Ato Institucional 5 (AI5) que proibia atividades ou manifestações de natureza política entre os anos de 1968 e 1978.

O processo de redemocratização dos países da América Latina ocorrido na década de 1980 dá maior autonomia para as instituições culturais. Assim, a Declaração de Quebec de 1984 veio reforçar as propostas da Mesa Redonda de Santiago e usa, pela primeira vez, o termo Nova Museologia. O termo reforça uma nova postura dos museus, atrelada a sua função social. Desta forma,

[a] museologia deve procurar, num mundo contemporâneo que tenta integrar todos os meios de desenvolvimento, estender suas atribuições e funções tradicionais de identificação, de conservação e de educação, a práticas mais vastas que estes objetivos, para melhor inserir sua ação naquelas ligadas ao meio humano e físico. (UNESCO, 1984).

A Declaração dá foco ao que chama de "museologias ativas", que se propõe a integração e interação com as populações locais dentro dos espaços museais, reforçando as preocupações científicas, culturais, sociais e econômicas. Desta forma, "este novo movimento põe-se decididamente ao serviço da imaginação criativa, do realismo construtivo e dos princípios humanitários defendidos pela comunidade internacional" (UNESCO, 1984).

De acordo com Chagas e Gouveia (2014) os ideais da Nova Museologia se espalharam pelo mundo nos anos de 1990. Porém, os autores desenvolvem que houve um embate entre teóricos de uma museologia mais tradicional e aqueles que adotaram os pressupostos da Nova Museologia. Com o passar dos anos os discursos se misturaram o que acarretou certa indiferenciação e indistinção entre as correntes da Museologia. Ou seja, certas práticas e metodologias da Nova Museologia foram adotadas por instituições de cunho tradicional sem o comprometimento ético e político. Segundo os autores:

A expressão virou moda e perdeu potência. E alguns daqueles que passaram a falar em nome da nova museologia passaram também a querer estabelecer regras definidoras do que é um novo museu, do 
que é um ecomuseu, do que é um museu comunitário, do que é um museu de território e com isso tentaram enquadrar a nova museologia no âmbito das práticas e procedimentos da museologia normativa. (CHAGAS; GOUVEIA, 2014, p. 13).

É preciso salientar que a Nova Museologia teve diferentes denominações para se referir ao conjunto de práticas pensadas em Santiago e Quebec, algumas delas foram: museologia popular, museologia ativa, ecomuseologia, museologia crítica, museologia comunitária, museologia dialógica. As múltiplas formas de nomear a Nova Museologia mostram, de certa forma, as fugas e resistências às tentativas de normatização e controle por nichos acadêmicos e instituições culturais. Segundo os autores:

Essas museologias indisciplinadas crescem de mãos dadas com a vida, elaboram permanentemente seus saberes e fazeres à luz das transformações sociais que vivenciam como protagonistas, por isso mesmo é no fluxo, no refluxo e no contrafluxo que se nomeiam e renomeiam, se inventam e reinventam, permanentemente (CHAGAS; GOUVEIA, 2014, p. 16).

A partir do exposto trataremos aqui brevemente de duas questões que permeiam os debates teóricos sobre a Museologia Social e a Sociomuseologia. A primeira é que de esses termos são utilizados, muitas vezes, como sinônimos. E a segunda é de que não existe Museologia Social, pois toda museologia se faz em sociedade e, é, portanto, social. Tolentino (2016, p. 31) tece algumas diferenciações entre os dois termos e diz que a Sociomuseologia é uma área interdisciplinar que "dá conta das questões que envolvem o campo da museologia social, como também reflete sobre a atuação dos museus de uma forma geral", ou seja, podem ser objeto de estudo da Sociomuseologia tanto as museologias libertárias e indisciplinadas como as museologias colonizadoras e tradicionais.

Já a Museologia Social é uma prática museológica que tem como foco o homem e suas relações com a sociedade, ao invés de focar nos objetos musealizados. Desta forma, é necessário tratar a produção de referências culturais e simbólicas, o ambiente e os problemas sociais de forma integral, para que os museus possam servir a suas comunidades. Diz o autor:

Para a museologia social, nas funções básicas de um museu, como preservar, pesquisar e comunicar, que devem ser executadas de forma participativa, os sujeitos sociais são a preocupação primeira, bem como os problemas sociais, econômicos, políticos e ambientais enfrentados pelas comunidades, com vistas à luta e à busca por seu desenvolvimento 
sociocultural. Isso representa o que os militantes da museologia social chamam a "função social" dos museus (TOLENTINO, 2016, p. 32).

No que tange a segunda questão, a resposta dada por Chagas e Gouveia (2014) é um pouco mais firme. Para eles, dizer que toda museologia é social é banalizar o sentido do adjetivo social e consequentemente retirar do campo dos museus sua dimensão histórica e política. Ademais, o que importa não é o fato dela existir em sociedade, mas sim dos compromissos sociais com os quais se vincula e assume e por isso, a museologia social se refere aos compromissos éticos, científicos, políticos e poéticos. Dizem os autores:

Estamos afirmando, radicalmente, a diferença entre uma museologia de ancoragem conservadora, burguesa, neoliberal, capitalista e uma museologia de perspectiva libertária; estamos reconhecendo que durante muito tempo, pelo menos desde a primeira metade do século XIX até a primeira metade do século XX, predominou no mundo ocidental uma prática de memória, patrimônio e museu inteiramente comprometida com a defesa dos valores das aristocracias, das oligarquias, das classes e religiões dominantes e dominadoras (CHAGAS; GOUVEIA, 2014, p.17).

A museologia social, portanto, cria compromissos para a redução de diversas mazelas sociais, como a redução de injustiças e desigualdades sociais; o combate aos preconceitos; à melhoria da vida coletiva, da coesão social e do sentimento de pertencimento; a utilização da memória, do patrimônio e do museu a favor das comunidades populares, movimentos sociais, indígenas e quilombolas.

Podemos notar que várias iniciativas foram criadas com esse viés, como o Museu da Maré, o Museu de Favela Cantagalo Pavão-Pavãozinho, o Museu Sankofa da Rocinha, o Museu Nega Vilma, todos no Estado do Rio de Janeiro, e os diversos Pontos de Memória por todo o Brasil. Além disso, no Rio de Janeiro e em São Paulo há a presença de Redes de Museologia Social formado por grupos, instituições e processos ligados a esta nova vertente museológica.

\section{O Museu de Favela Cantagalo Pavão-Pavãozinho}

O Museu de Favela Cantagalo Pavão-Pavãozinho (MUF) é uma organização não governamental fundada em 2008 no contexto do Programa de Aceleração do Crescimento (PAC) e do PAC Social que era voltado para o desenvolvimento das favelas no Rio de Janeiro. O museu se encontra nas encostas do maciço do Cantagalo, entre os bairros de Copacabana, Ipanema e Lagoa na Zona Sul da cidade do Rio de Janeiro.

Além do trabalho de revisão bibliográfica, foram feitos trabalhos de cunho etnográfico no MUF ao longo do ano de 2017, totalizando três visitas em dias e grupos diferentes. Esclareço para o leitor que não foram realizadas entrevistas formais, mas diálogos com os mediadores e moradores ao longo dos percursos que duram 
aproximadamente três horas. As questões apontadas aqui se referem ao dia em que o idealizador e curador do projeto Casas-Tela, o grafiteiro Carlos Esquivel, conhecido como Acme se juntou a Sidney Silva na mediação.

O MUF segue uma tendência da museologia contemporânea ao investir na ideia de museu território, museu comunitário e museu de percurso ${ }^{3}$. O museu foi pensado como uma galeria a céu aberto, cujo percurso é composto por graffiti nas paredes das casas dos moradores, as chamadas Casas-Tela, com temáticas de rememoração das origens dos habitantes do local. O MUF foi uma das estratégias pensadas para fomentar o turismo na região.

É preciso salientar que o MUF foi criado no contexto do Plano Nacional de Museus, assinado em 2003 que tinha como objetivo:

Promover a valorização, a preservação e a fruição do patrimônio cultural brasileiro, considerado como um dos dispositivos de inclusão social e cidadania, por meio do desenvolvimento e da revitalização das instituições museológicas existentes e pelo fomento à criação de novos processos de produção e institucionalização de memórias constitutivas da diversidade social, étnica e cultural do país. (BRASIL, 2003, p. 8).

O MUF se pauta nos princípios da Nova Museologia e da Museologia Social para sua atuação e gestão, feita por moradores da comunidade. Segundo o site da instituição:

Nesse primeiro museu territorial e vivo sobre memórias e patrimônio cultural de favela do mundo, o acervo são cerca de 20 mil moradores e seus modos de vida, narrativas de parte importante e desconhecida da própria história da cidade do Rio de Janeiro. A qualidade da visita ao Museu de Favela será tanto melhor quanto melhor for a qualidade de vida local. O MUF defende a dignidade das condições de vida local e luta contra a segregação social das favelas. ${ }^{4}$

A curadoria do projeto das Casas-Tela ficou a cargo do grafiteiro e morador do local Carlos Acme e contou com trabalhos do próprio Acme, de Kajaman, Eco, Carlos Bobi e outros grafiteiros conhecidos na cena do Rio de Janeiro. A grande questão de um museu comunitário é que ele seja pensado pelo e para os moradores em busca de um desenvolvimento econômico, social e cultural da comunidade onde o museu está instalado.

\footnotetext{
${ }^{3}$ Para mais informações sobre o processo de criação do MUF remeto o leitor a excelente dissertação de Rodrigues (2015) intitulada Registros de Memória em Arte Fugaz: o Graffiti das Casas-Telas do Museu de Favela (20102014).

${ }^{4}$ Retirado de https://www.museudefavela.org/sobre-o-muf/. Acesso em 16/01/2019.
} 
Chagas (2009) traz como grande questão da museologia social a mudança na ideia de que os museus devem ser abertos para todos, para a ideia de que todos os grupos sociais podem se utilizar desta ferramenta em prol de suas narrativas, histórias e memórias. $\mathrm{O}$ museu passa a ser concebido por essa vertente como um instrumento, uma ferramenta utilizada para se chegar a determinados objetivos, normalmente em prol do desenvolvimento comunitário, seja ele material ou imaterial.

O principal atrativo do museu são o circuito das Casas-Tela e o circuito eco trilha Caminho do Alto. O museu também conta com duas bases operacionais onde mantém exposições permanentes e itinerantes. Como salientado anteriormente, o diferencial do MUF é que ele é organizado e tem como profissionais atuantes no museu os habitantes do local. Alguns líderes culturais lidam da gestão, enquanto os mediadores dos circuitos podem ser moradores.

Em uma das visitas à favela, Sidney Silva, conhecido como Sidney Tartaruga, um dos diretores do museu e mediador cultural, salientou que há a ideia da instalação de placas indicando o circuito das Casas-Tela já que muitos visitantes não fazem contato com o museu para realizar as visitas e acabam se perdendo dentro da favela. Em alguns casos como esses os moradores que não são diretamente ligados ao museu, como em quadros de funcionários, passam a fazer a mediação.

Cabe salientar que as favelas do Cantagalo e Pavão-Pavãozinho receberam em dezembro de 2009 uma Unidade de Polícia Pacificadora (UPP). A lógica da UPP era de substituir os confrontos armados esporádicos pela ocupação permanente dos territórios e de sufocar com maior força o tráfico de armas e consequentemente o tráfico de drogas. Além disso, há a ideia de se fomentar a melhora nas relações entre policiais e moradores através da chamada polícia de aproximação (IORIO, 2014).

A instalação da UPP nas duas favelas eliminou em um primeiro momento as trocas de tiros e sufocou o narcotráfico da região dominada pela facção Comando Vermelho desde meados dos anos de 1990, que deu unidade as duas comunidades, anteriormente pautadas pelas disputas de grupos de moradores e de quadrilhas distintas.

A relação de rivalidade entre Cantagalo e Pavão-Pavãozinho é anterior ao início do tráfico na região e, inclusive, orientou a forma como os antigos bandidos locais, as chamadas "quadrilhas", atuaram na região. Tais quadrilhas, no entanto, foram substituídas pelo Comando Vermelho, que após dominar os pontos de venda de drogas das duas favelas, buscou, ao seu modo, unificá-las, alterando a dinâmica da vida local. (CUNHA apud PORTILHO, 2016, p. 194-195).

Portilho ainda salienta que a unidade territorial produzida primeiramente pelos narcotraficantes do Comando Vermelho foi apropriada pelo Estado quando se deu a implantação da UPP. Diz a autora: 
Esta apropriação seguramente se dá através da ação policial naquela região que, para traçar as estratégias de enfrentamento ao tráfico, levou em conta a sua maneira de operar o território. Posteriormente, foi adotado o formato "Complexo do Pavão-Pavãozinho Cantagalo" para o desenvolvimento de ações do Programa de Aceleração do Crescimento, uma atualização daquela unidade dos territórios produzida pelo tráfico que impactou o desenho das ações promovidas pelo MUF. (PORTILHO, 2016, p. 195).

Iorio (2014) ressalta em pesquisa realizada no Cantagalo Pavão-Pavãozinho que os moradores apontam que desde a instalação da UPP houve aumento considerável da circulação de pessoas de fora da favela, o aumento do turismo, a abertura de lojas, bancos, hostels e pousadas. A autora salienta que houve melhorias e falhas na convivência entre policiais e moradores. A principal questão é de que não houve planejamento subsequente para a instalação de serviços na região, apenas a presença dos policiais.

Quando a permanência de policiais na favela, sua militarização e a continuidade de seu tom agressivo e violento não vem acompanhada de melhorias nos serviços públicos e na convivência entre moradores, além de uma tentativa ativa de cooperação entre policial e morador, a UPP, lentamente, caminha para a sua ruptura, declínio e perda de ideologia. Mesmo que a bandeira da "paz" venha a ser pintada pela imprensa e pelos discursos governamentais, essa nova forma de poder e de policiamento, tingida pelo estandarte do fim do tráfico armado e do confronto bélico, se reforça, ainda mais, uma prática de segurança segregacionista, em que não se pretende uma real integração entre as "partes" dicotômicas de uma mesma cidade (asfalto-favela). (IORIO, 2014, p. 15).

É preciso destacar que no ano das visitas foi possível observar mais a presença de pessoas armadas ligadas ao narcotráfico do que de policiais militares. Desta forma, observase que o projeto teve pouco êxito no que tange a erradicação do tráfico de armas e no ano de 2018 o Gabinete de Intervenção Federal que atuava no Rio de Janeiro decidiu acabar com metade das UPPs ${ }^{5}$.

Dessa maneira, a instalação e manutenção do MUF se dão através da negociação entre as diversas forças e grupos dentro da favela: policiais, narcotraficantes e moradores. Porém, como é salientado por Rita de Cássia Santos (2014, p.329), uma das fundadoras do museu, "destaca-se o foco de atuação do Museu junto ao território e aos moradores, em

\footnotetext{
${ }^{5}$ Mais dados estão disponíveis em: https://g1.globo.com/rj/rio-de-janeiro/noticia/gabinete-de-intervencao-no-rjdecide-acabar-com-metade-das-upps.ghtml. Acesso em 10/05/2019.
} 
sinal de respeito e valorização do saber-fazer e de suas memórias, com foco na dignidade e no reconhecimento do processo social afirmativo de resistência".

Apesar dessa necessidade de negociação, Portilho (2016) ressalta que a temática do tráfico de drogas e da violência não é abordada no circuito das Casas-Tela e nem tratada pelos gestores do museu. Diz a autora:

Em relatos informais durante o trabalho de campo, quando perguntados sobre estes temas, os diretores do museu afirmaram que são assuntos que trazem dor e sofrimento e a opção do museu é por não abordá-los para não gerar desconforto aos moradores. Na concepção dos idealizadores do MUF, projetar o futuro, que é uma dimensão constitutiva fundamental de seu projeto memorial, passa por esquecer determinados elementos do passado de sofrimento. Ao mesmo tempo, é preciso considerar que por ser um empreendimento voltado para o turismo, a evocação do tráfico e da violência poderia ser um limitador. Consequência destas opções é que não há lugar para a memória exemplar, no sentido de que o passado do tráfico e suas vítimas não pode ser evocado para pensar o presente e o futuro (PORTILHO, 2016, p.187).

O que nos interessa no caso do MUF é a instituição de novas práticas e projetos museológicos e museais na cidade do Rio de Janeiro que contrastam com a lógica da espetacularização que aconteceu com os museus da Praça Mauá, mais especificamente, o Museu do Amanhã e o Museu de Arte do Rio. Não é questão de exacerbar um modelo em detrimento de outro, mas reconhecer que novos atores emergem na cena cultural e museal e não mais apenas no sentido de serem incluídos pelos espaços tradicionais, mas também de serem produtores de seus próprios patrimônios, museus e discursos.

A partir da experiência dos museus de favelas e dos museus comunitários Chagas, Studart e Storino (2014, p.18-19) desenvolvem a ideia de cidadania museal que "pode ser compreendida como o exercício explícito do direito à memória, ao patrimônio, à coleção, ao museu e à vida; trata-se de um dispositivo de luta, de afirmação e de resistência das comunidades populares e tradicionais".

É preciso salientar que às vezes os percursos feitos pelos mediadores não são iguais, ou seja, cada visita ao museu é única. Quando se entra em contato com o museu para agendar a visita há a opção de fazer visitas normais e visitas técnica, para as pessoas ligadas às áreas de museus, turismo e antropologia. Os valores das duas modalidades são diferentes.

Em uma das visitas técnicas realizadas por mim, tivemos dois mediadores, Sidney Tartaruga e Carlos Acme. O interessante de se ter um dos idealizadores e curador do circuito das Casas-Tela são as histórias e ideias por trás da confecção dos murais. O circuito conta a história dos moradores e da favela através de vinte e sete Casas-Tela. 
A denominação Casa-Tela parece ter vindo realmente da ideia do museu de artes tradicional, que possui quadros de pintores famosos. A tela seria a casa do morador, o artista valorizado, o grafiteiro. O circuito surgiu assim com o objetivo de preservar memórias da favela que poderiam se perder e divulgá-las para outras pessoas. (RODRIGUES, 2015, p. 97).

Dois aspectos interessantes permeiam a confecção das Casas-Tela. O primeiro diz respeito à mediação que é tecida para a pintura das casas que reúne os moradores, os artistas e os responsáveis pelo museu para definir conteúdos e temáticas. Rodrigues (2015) ressalta que houve bastante dificuldade em obter autorização em um primeiro momento, visto que o museu, recém-criado, pedia que os moradores assinassem um termo de autorização de pintura. O problema era que à época algumas remoções estavam acontecendo por conta do PAC Social e muitos moradores não assinavam nenhum documento com medo de serem removidos. Mattos (2014) ressalta que desde 2008 foram removidas cerca de três mil famílias de diversas favelas da cidade do Rio de Janeiro sob a justificativa de que as ocupações estavam em áreas de interesse da Prefeitura e do Estado para a realização da Copa do Mundo e das Olimpíadas. Apesar da desconfiança de parte dos moradores o projeto do museu teve sequência e foi abraçado por diversos habitantes.

Outro aspecto que suscitou certa discussão foi a da restauração dos painéis por conta da deterioração dos mesmos. A princípio a ideia de restauração de um graffiti soa um tanto estranha. Alguns grafiteiros como Carlos Bobi, Fernando Cazé e o próprio Acme exacerbam o caráter efêmero da arte de rua. Como então restaurar esses trabalhos? A restauração a que Acme se refere não tem o sentido tradicional da restauração em outros trabalhos de artes plásticas. A restauração dos graffiti do MUF consiste no apagamento dos trabalhos e a pintura de um novo painel com a mesma temática, sempre havendo diálogo entre os moradores das Casas-Tela e os artistas.

O circuito das Casas-Tela constitui uma forma de novos atores culturais contarem as suas próprias histórias. Isto quer dizer que os indivíduos e grupos outrora marginalizados ou nas periferias, e as minorias, têm direito a sua voz e expõem suas memórias subterrâneas, que se opõem à memória oficial.

A fronteira entre o dizível e o indizível, o confessável e o inconfessável, separa, em nossos exemplos, uma memória coletiva subterrânea da sociedade civil dominada ou de grupos específicos, de uma memória coletiva organizada que resume a imagem que uma sociedade majoritária ou o Estado desejam passar e impor. (POLLAK, 1989, p. 8) 
Desta forma, ao contar a história e as dificuldades dos moradores da favela, o circuito é dividido em quatro temáticas: origem e história; lazer, cultura e convivência; dificuldades de sobrevivência; e pontos históricos. Segundo o site do museu:

O propósito dessas expressões artísticas é contar a saga, a memória, a história das favelas que compõem o território, desde os escravos fugidos que se acoitavam no Maciço do Cantagalo, passando pelas primeiras construções de barracos no início de 1907, até os dias de hoje, quando mais de 20 mil moradores desse museu territorial lutam contra a segregação social das favelas no contexto da cidade e a favor da sua inclusão funcional urbana e socioeconômica no contexto e na vida social dos bairros de Ipanema e Copacabana, destinos turísticos mundialmente famosos.(MUSEU DA FAVELA, s/d) ${ }^{6}$

São essas memórias subterrâneas que nos importam na análise do circuito como possibilidades de construção identitária, agrupadora de pessoas que constituem os laços comunitários e das narrativas periféricas que podem contar, fornecendo novas histórias e visões de mundo que, normalmente, contrariam ou não compartilham das versões oficiais.

Assim, vemos que o processo de construção da memória é feito pelos diversos atores presentes no território e está em constante diálogo e reinterpretação. Os graffiti das Casas-Tela mostram a diversidade e multiplicidade de discursos outrora renegados e reafirmam a identidade territorial dos moradores da favela, que agora, contam suas histórias por si mesmos e não através de outros.

Outra característica interessante dos graffiti das Casas-Tela é a presença de rimas na estrutura de cordéis, como forma de homenagear os moradores nordestinos da favela, presentes principalmente no lado do Pavão-Pavãozinho. Ademais, é possível notar que em diversos painéis há a presença do galo e do pavão, salientando a união entre as três comunidades. O circuito também é bem dividido sendo: treze casas do lado do Cantagalo e quatorze do Pavão-Pavãozinho (RODRIGUES, 2015).

Atualmente o MUF faz parte da Rede de Museologia Social do Estado do Rio de Janeiro que conta com representantes do Museu da Maré, Museu Vivo de São Bento, Museu Sankofa da Rocinha, Museu do Horto, Ecomuseu Nega Vilma, dentre outros.

\section{Novos atores na cidade}

É possível notar que foram criados vários museus de favelas ou museus comunitários na cidade do Rio de Janeiro a partir dos anos 2000. Apontamos o Museu da Maré criado em 2006, o Museu de Favela em 2008, o Museu da Rocinha Sankofa em 2011, o Museu do Horto Florestal em 2010.

\footnotetext{
${ }^{6}$ Retirado de https://www.museudefavela.org/visitacao-integrada/. Acesso em 16/01/2019.
} 
Esse movimento de criação de museus, como já dito anteriormente, parte das noções e conceitos trazidos pela Museologia Social. Ademais, podemos ver que as favelas e comunidades passam a disputar as narrativas oficiais e mostram um desejo de se inserir nos circuitos das cidades. Essas iniciativas também alargam a noção de patrimônio e mostram que as favelas têm muito mais potência e diversidade do que os problemas apontados pelo poder público e pela mídia.

Além dos mencionados museus, vemos também o aparecimento de galerias de graffiti a céu aberto nos morros da Providência e Babilônia, além do tradicional evento Meeting of Favela que acontece na Vila Operária em Duque de Caxias, que visam através da arte, transformar os espaços das comunidades, fomentar o comércio e o turismo e contar a história local.

Barbosa e Silva (2013) apontam que as favelas eram consideradas nos discursos hegemônicos como espaços com "ausência de civilidade e urbanidade". As favelas, por essa visão, são os lugares da falta e não fazem parte das regras da cidade. Os autores dizem que "tais pressupostos reduziram (e ainda reduzem) as favelas às condições de territórios precários, ilegais, inacabados, desordenados e inseguros: o avesso da cidade" (BARBOSA; SILVA, 2013, p. 188, grifo dos autores).

O que esses museus e galerias fazem é tentar alterar a visão do senso comum sobre as favelas e inseri-las nos circuitos culturais das cidades, mostrando suas potencialidades e a diversidade de práticas sociais e culturais. É preciso salientar que setores mais conservadores da museologia não consideram essas experiências como experiências museais por excelência visto que os objetos musealizados não são o foco central desses espaços. Chagas (2006) ressalta que os museus são arenas de conflitos, campos de disputa onde a tradição e a contradição se enfrentam. É preciso salientar que os movimentos de memória estão sempre ligados a jogos de poder. Assim, memória e poder compõem dois movimentos que se cruzam na construção de narrativas preservacionistas e patrimoniais.

A aceitação do museu como arena e campo de luta está bastante distante da ideia de espaço neutro e apolítico de celebração da memória daqueles que prematura e temporariamente alardeiam os louros da vitória. No entanto, desde o nascedouro, os museus - mesmo estruturados sobre bases positivistas de celebração da memória de vultos vitoriosos e de culto à saudade de heróis consagrados por "tradição inventada" - estão indelevelmente marcados com os germes da contradição e do jogo dialético (CHAGAS, 2006, p. 30).

Podemos compreender que os museus constituem um campo de disputa de significados, símbolos, histórias e narrativas oficiais e não oficiais que tem relação direta com as ideias de poder e memória. Em diversos textos teóricos da museologia só se dá ênfase a dimensão mnemônica dos museus, deixando o poder de lado. 
Esse é um dos motivos pelos quais os autores ligados à Museologia Social reforçam seu caráter ético e político. Não se pode esquecer que os museus são instrumentos que servem a determinados propósitos e estes podem ser libertários ou reacionários. Porém, não é o fato de o museu ser pautado por um modelo tradicional que o faz adotar também a museologia tradicional. Podemos citar o Museu da República no Rio de Janeiro, antiga residência dos presidentes da república antes da criação de Brasília, que têm projetos de parcerias com o Museu da Maré e o Museu Nami, localizado na comunidade Tavares Bastos.

Ademais, o Museu da República realiza, em sua nova gestão, encontros com os usuários do museu e do jardim para ouvir as demandas da comunidade e aumentar a participação social. Diz Chagas:

Trabalhar os museus e a museologia nesta perspectiva (do poder da memória) implica afirmar o poder dos museus como agências capazes de servir e de instrumentalizar indivíduos e grupos de origem social diversificada para o melhor equacionamento de seu acervo de problemas. O museu que abraça esta vereda não está interessado apenas em democratizar o acesso aos bens culturais acumulados, mas, sobretudo, em democratizar a própria produção de bens, serviços e informações culturais. O compromisso, neste caso, não é tanto com o ter e preservar acervos, e sim com o ser espaço de relação e estímulo às novas produções, sem procurar esconder o "seu sinal de sangue" (CHAGAS, 2006, p. 33).

A disputa nesse sentido, diz respeito também a integração desses museus de favela com a cidade. Esses museus são feitos pelos moradores e para eles, mas isso não quer dizer que eles têm que se fechar em uma bolha restrita. O que nos chama atenção é que a produção desses espaços museais é heterogênea e diversificada, pautada nas especificidades de cada território. Território este que não é dado, mas praticado. O geógrafo Milton Santos (2000) ressalta que o território não é um dado neutro nem um ator passivo, mas que pode ser produtor de solidariedades e identificação - interna aos territórios - ou zonas de fragmentação com parâmetros exógenos que buscam apenas a maior racionalidade econômica possível.

No caso dos espaços mencionados, podemos ver que são mais pautados por lógicas da solidariedade do que da competitividade ou fragmentação. Os projetos, como o do MUF, tentam trazer o desenvolvimento social e econômico para as favelas, mas mantendo os laços de sociabilidade, as culturas locais e os modos de vida existentes no território. A principal preocupação é com os moradores e com o território. Rita de Cássia ressalta que 
É bom frisar que para cada ação do Museu de Favela são feitas mediações com os moradores; aquilo que não é bom para o morador, não é bom para o MUF. Até porque todas as ações têm como foco o morador, o seu saber-fazer, as suas memórias, a sua dignidade, o reconhecimento do processo social afirmativo de resistência, a identidade coletiva, a luta por cidadania, a busca pela valorização do território, a inclusão definitiva da favela no cenário da cidade do Rio de Janeiro. (SANTOS, 2014, p. 333).

Podemos pensar com Bocayuva (2018) que existe um modelo de cidade neoliberal que se espalha pelo mundo e que foi adotada pelo Rio de Janeiro no que tange as modificações urbanas elaboradas no contexto dos megaeventos esportivos da Copa do Mundo de 2014 e das Olimpíadas em 2016. Esse modelo, pautado na imagem da cidade como mercadoria, de uma cidade vendável para a iniciativa privada e para o turismo irrestrito adotou os grandes museus como forma de publicizar sua imagem e apostou na remoção das favelas e na instalação de UPPs em prol da especulação imobiliária.

Nesse panorama, é possível pensar os museus de favela, e especificamente o MUF, como projetos locais que se distinguem da lógica global da cidade neoliberal. Nesse sentido, e reforçando a fala de Chagas, o museu é entendido como instrumento de disputa. Diz Bocayuva:

As intensidades e ritmos dos ciclos de acumulação e das projeções das intervenções de apropriação do espaço visam atrair o capital que comprime as várias periferias. Nas zonas de exclusão, sujeitos e objetos revertem, invertem e, até mesmo, pervertem a disputa, que aparece como crise e explosão das metrópoles que se fragmentam (BOCAYUVA, 2018, p. 49)

Essas formas de resistência à homogeneização das cidades e das produções culturais possibilita a construção não só de narrativas, mas de saberes contra-hegemônicos que "permite pensar em espaços de esperança ou territórios existenciais temporários" (Ibidem). Não se trata de romantizar as favelas, nem de negar os problemas estruturais que muitas apresentam. Nem de se fazer um tipo de turismo que ficou conhecido no início dos anos 2000, os favela tour feito por guias de fora das favelas, explorando a ideia do exótico nas comunidades, principalmente por levar turistas estrangeiros em carros abertos que lembram os safáris feitos em outros países.

Trata-se de se afirmar as favelas como espaços integrantes das cidades a partir da organização dos moradores desses locais, de uma solidariedade horizontal, que é pensada pelos e para os moradores. 
Assim, com base na atuação comunitária e participativa, surgiu a visão de futuro que se tornou o macro-objetivo do MUF, ou seja, reconhecer e afirmar aquilo que o morro já é: um Monumento Carioca; um patrimônio fundamental para a história da cidade e das favelas; uma referência para a cultura popular e para a compreensão da formação musical da cidade, das origens culturais do samba, da cultura do migrante nordestino, da cultura negra, das artes visuais e da dança. (SANTOS, 2014, p.330).

Nesse sentido, é trazer para a discussão a visão dos moradores do PavãoPavãozinho Cantagalo por eles mesmos, como produtores de cultura, produtores de história e produtores de memória. Como foi salientado esse não é um processo sem choques e sem disputas. Faz-se necessário pensar em parcerias e projetos que fortaleçam essas iniciativas. Além da já citada Rede de Museologia Social, atualmente, o MUF conta com apoio e reconhecimento do Instituto Brasileiro de Museus (IBRAM) e parcerias com Universidades da cidade do Rio, como a UFRJ, a UFF, a UNIRIO e a PUC que mescla saberes populares e acadêmicos.

No que tange as discussões acerca da cidade, os museus de favela colocam em jogo não só narrativas, mas outras formas de viver e enxergar a metrópole que não parte da ideia dicotômica presente na cidade partida de asfalto $\mathrm{x}$ favela, onde a ultima é tida como uma área fora da urbe. Bocayuva (2018) reforça que não se pode pensar as cidades apenas pelas zonas ricas e oprimir zonas pobres e iniciativas que fogem do viés regulatório do modelo da cidade global. Diz o autor:

A questão da periferia que se constitui como um motor produtivo e espaço de lutas mostra que, para podermos pensar o urbano, as leituras devem se deixar atravessar pelos e se relacionar com os diversos atores ditos subalternos que povoam a cena contemporânea, destacando os contextos e as forças de produção que incidem em todos os territórios afetados pela produção do espaço com toda a diversidade de forças e agendas que se chocam (BOCAYUVA, 2018, p. 58).

Seguimos com o pensamento do autor que considera que os museus e o campo de estudo museológico aparecem como espaços de narração e construção de modos de expressão e sensibilização que têm efeito sobre corpos e mentes que operam relações entre objetos estéticos, espetáculos, performances e público. Dessa forma, a mudança de uma museologia tradicional pautada em objetos e prédios para museologias críticas pautadas em territórios e sujeitos também ajuda a produzir novas visões sobre determinados territórios citadinos. "A museologia crítica rompe com o caráter estático e acompanha a performance e o movimento dos corpos, descontruindo os lugares, ampliando o campo e o enfoque 
antropológico, introduzindo a complexidade e o caos na narrativa" (BOCAYUVA, 2018, p. $61)$.

Podemos considerar que o MUF se propõe a ser uma vertente institucional da preservação, comunicação e valorização das histórias e saberes da favela que combate estratégias de ocultamento e invisibilização derivadas de iniciativas do poder público estadual e municipal. E que faz parte de um projeto dinâmico, pautado no movimento, na mudança e na vida.

O Museu de Favela é uma experiência radical de celebração da vida, de comprovação de que na favela existe felicidade, existe vida, solidariedade e amizades verdadeiras, o contato direto e constante, o papo de beira de caminho, o churrasco na laje, a feijoada coletiva, a casa cheia de gente, a comida farta, tudo isso é reverenciado pelo Museu de Favela, tudo isso é nosso, é legítimo, é a cara da favela. (SANTOS, 2016, p. 334).

\section{Sobre o Patrimônio}

No âmbito museológico, normalmente se atribui memória e esquecimento aos objetos, relatos, imagens e outros. Porém, assim como os historiadores mudaram sua visão, assumindo que os documentos não falam sozinhos, outra ótica vem sendo utilizada, em parte, nas instituições museais. Digo em parte, pois ainda há uma forte vertente preservacionista que se preocupa muito mais com os objetos do que com as relações que podem ser estabelecidas. Mais uma vez me refiro ao viés preservacionista que se encerra nele mesmo. A mesma lógica pode ser aplicada aos monumentos e ao patrimônio material de forma geral.

A memória e o esquecimento não estão nas coisas, mas nas relações entre os seres, entre os seres e as coisas, entre as palavras e os gestos etc. É necessária a existência de uma imaginação criadora para que as coisas sejam investidas de memória ou lançadas no limbo do esquecimento. (CHAGAS, 2009, p. 23)

A partir da citação de Chagas, podemos tecer algumas relações. Se a memória se dá a partir da relação entre os seres, não é a mesma para diferentes seres, sejam eles humanos ou não humanos. Sendo assim, não há nestas relações uma memória absoluta, única e compartilhada por todos. As relações anteriores, o ambiente cultural e social e as ligações dos sujeitos com os outros sujeitos e com os objetos norteiam a concepção e a rememoração que irão tecer.

Corroborando com essas ideias, Jeudy (1990) argumenta que a memória não segue, necessariamente, uma ordem cronológica e que pode ser contraditória, confusa, irruptiva e projetiva. Desta forma, "as funções culturais das memórias ditas coletivas não correspondem senão a uma maneira possível, dentre outras, de estabelecer uma ordem 
dinâmica dos traços mnésicos." (JEUDY, 1990, p.19). Assim, os museus e o patrimônio, normalmente considerados como os locais da concentração da memória, não são as únicas modalidades para rememoração, mas podem ser consideradas mais complexas que outras, visto que, em geral, são espaços organizados para a evocação da memória e das diversas referências culturais, além de contribuírem para a construção do conhecimento.

Outra referência trazida por Jeudy (1990) é de que as memórias coletivas constituem uma relação evidente com as identidades culturais. Relação esta que pode ser de construção e de diálogo ou então de imposição, quando se evoca e administra uma memória que se impõe como o espelho das comunidades. Esse espelho, contudo, não reflete o que elas são, mas sim o que deveriam ser. Produz-se uma aparência de ordem. Isso nos traz a ideia do desprezo pelo cotidiano que, normalmente, se dá nas teorizações e análises das realidades locais. Considerando-se que, em muitos casos, as políticas de memória fazem parte desta conjuntura do dever ser, Jeudy aponta para a emergência de novos espaços museais que dão novas perspectivas e possibilidades para os sujeitos e não apontam modelos prontos de ser. É o caso dos museus citados anteriormente. "Os sujeitos sociais são então convidados a uma interpretação ativa, a um trabalho de simbolização que deveria incitá-los a resistir aos determinismos de uma história que exclui suas habilidades e maneiras de pensar." (JEUDY, 1990, p. 32). Essa nova vertente da museologia, citada por ele, vai ao encontro da já mencionada cidadania museal.

O professor e antropólogo José Reginaldo Santos Gonçalves, em uma de suas reflexões sobre patrimônio, diz:

Afinal, os seres humanos usam seus símbolos, sobretudo para agir, e não somente para se comunicar. O patrimônio é usado não apenas para simbolizar, representar ou comunicar: é bom para agir [...] Não existe apenas para representar ideias e valores abstratos e ser contemplado. $\mathrm{O}$ patrimônio, de certo modo, constrói, forma as pessoas. (GONÇALVES, 2002, p.31)

A partir dessa ideia, vemos que os patrimônios em suas diversas tipologias são agentes transformadores das realidades e das atitudes dos diversos grupos que integram nossa sociedade. O patrimônio é algo reconhecido pelos moradores de um bairro, ou de um território determinado, que contribui para a formação das identidades desses diversos grupos e que não se engessa na preservação, que muitas vezes impõe uma nova relação entre os sujeitos locais e o bem patrimonializado. Na visão de Jeudy (1990, p.8-9):

O consenso estabelecido em torno da conservação dos patrimônios é abalado pela diversidade e contradições das representações do devir da memória das sociedades. A organização e o tratamento dessas formas da memória coletiva é que contêm os germes de uma crítica da própria ideia 
de patrimônio. Não se trata mais de saber por que e como ele se conserva, mas sim de apreender as funções sociais das memórias dentro da metamorfose das sociedades.

Dessa forma, apreendemos como patrimônio aquilo que afeta ou é afetado pelos diversos segmentos da sociedade, ou, para Bruno Latour (2004), o que põe as pessoas em movimento, seja por objetos ou artefatos humanos ou não humanos. Posto isso, o patrimônio seria esse "agente não humano" que nos move, que torna importante a luta por reconhecimento, que nos faz agir, querer que o mesmo seja preservado em prol das diversas comunidades, diversos espaços e territórios, numa relação sempre positiva. Aquele que não se envolve nessas relações fica alheio, insensível, mudo, morto.

Chagas (2006) também ressalta a importância da relação dos usuários com o bem cultural. Para ele os laços criados são mantidos e ampliados e ocorrem novas significações e ressignificações. Segundo ele:

O uso social do bem cultural preservado pode ser compreendido como a possibilidade do mesmo ser utilizado como referência de memória por determinados segmentos sociais, ou ainda como recurso de educação, de conhecimento e de lazer para uma determinada coletividade. Consequentemente, o uso social do bem cultural passa necessariamente através da democratização do acesso ao patrimônio cultural, da democratização da produção cultural e da incorporação ao patrimônio cultural brasileiro de representações de memória de origens sociais diversas. (CHAGAS, 2006, p. 112)

Através dessas ideias e das apresentadas anteriormente, vemos que os museus comunitários e os museus de favela trazem toda uma discussão acerca das noções de patrimônio, de museu e da função social desses espaços, mostrando que há um mundo de possibilidades fora dos moldes tradicionais da museologia, além de se mostrarem as potencialidades de locais excluídos pela lógica dicotômica da cidade partida.

\section{Considerações Finais}

A partir do exposto vemos que a área dos museus passou por várias transformações no que tange as práticas e teorias e se abriu para diversos modelos e modos de fazer e pensar os museus, o patrimônio e a memória.

Ademais, a Museologia Social vem reafirmar o compromisso social, ético e político dos museus com os diversos públicos e principalmente como possibilidade de desenvolvimento comunitário através de iniciativas feitas pelos próprios habitantes dos locais musealizados. Essa vertente museológica não se contenta em apenas democratizar o acesso aos museus e centro culturais, mas é mais preocupada em democratizar a produção 
de bens e instituições culturais, que são usadas como instrumentos em prol de certos objetivos locais.

Iniciativas como as do MUF, do Museu da Maré e de outros museus comunitários e museus de favela se mostram como uma importante ferramenta de resistência e de produção de narrativas para conseguir disputar o campo da memória. Através deles, a história de grupos, muitas vezes, marginalizados é contada por eles mesmos, contrariando histórias oficiais e contribuindo para mudanças no senso comum e no imaginário social.

Além disso, a entrada desses novos atores nos circuitos citadinos e na dinâmica dos jogos de poder e da memória traz à luz novos conceitos e formas de se enxergar os usos dos patrimônios e dos museus, mostrando que os museus se pautam mais pela sua diversidade do que pela sua homogeneidade.

Os museus são em devir. Esta afirmação, aparentemente simples, implica entre outras coisas, a compreensão de que os museus estão em movimento e são - ou podem ser - ao mesmo tempo, produtores, irradiadores e estimuladores do conhecimento, bem como conectores e articuladores de diferentes experiências sociais e espaçotemporais.[...]Em devir os museus são potência, ainda que possam ser capturados pelo sistema; são minas propícias à criação do novo, ainda que possam reproduzir e até mesmo exaltar os equívocos do passado (CHAGAS; STORINO; STUDART, 2014, p. 12).

Ou seja, os museus estão em constante mudança, podendo ser centros que produzem, estimulam e vulgarizam conhecimentos, além da possibilidade de servirem à construção identitária e memorial de grupos outrora na periferia das produções discursivas institucionais. Trate-se no caso do MUF de integrar a dinâmica do turismo na cidade, mas através do viés do morador e do território e não de representações românticas ou do reforço de estereótipos e do exótico.

Nesse sentido, os museus podem situar-se nas mais divergentes posições culturais, sociais, políticas e educacionais, mas o que a Museologia Social reforça é o caráter transformador dos museus enquanto ferramenta de desenvolvimento territorial em prol de grupos populares e tradicionais.

\section{Referências Bibliográficas:}

BARBOSA, Jorge; SILVA, Jailson. As favelas como territórios de reinvenção da cidade. Cadernos do Desenvolvimento Fluminense, Rio de Janeiro, n. 1, fev. 2013.

BRASIL. Ministério da Cultura. Bases para a Politica Nacional de Museus: Memória e Cidadania. Brasília: Minc, 2003.

BOCAYUVA, Pedro Cláudio. Museologia e o fenômeno urbano: reflexividade e recombinação para pensar o novo ciclo social. In: CHAGAS, Mario; PIRES, Vladimir. 
(Orgs). Território, museus e sociedade: práticas, poéticas e políticas na contemporaneidade. Rio de Janeiro: UNIRIO; Brasília: Instituto Brasileiro de Museus, 2018.

CHAGAS, Mário. Há uma gota de sangue em cada museu: a ótica museológica de Mário de Andrade. Chapecó: Argos, 2006

A imaginação museal: Museu, memória e poder em Gustavo Barroso, Gilberto Freyre e Darcy Ribeiro. Rio de Janeiro: MinC/IBRAM, 2009

CHAGAS, Mário; STUDART, Denise; STORINO, Claudia. (orgs). Museus, biodiversidade e sustentabilidade ambiental. Rio de Janeiro: Espirógrafo Editorial: Associação Brasileira de Museologia, 2014.

CHAGAS, Mário; GOUVEIA, Inês. Museologia social: reflexões e práticas (à guisa de apresentação). Cadernos do CEOM, Santa Catarina, v. 27, n.41, p. 9-22, 2014.

CHAGAS, Mário; PRIMO, Judite; ASSUNÇÃO, Paula; STORINO, Claudia. A museologia e a construção de sua dimensão social: olhares e caminhos. Cadernos de Sociomuseologia, Lisboa, v. 55, p. 73-102, 2018.

GONÇALVES, José Reginaldo Santos. O patrimônio como categoria de pensamento. In: ABREU, R.; CHAGAS, M (orgs). Memória e patrimônio: ensaios contemporâneos. Rio de Janeiro: Lamparina, 2009.

IORIO, Natalia. O silêncio pacificador: a questão das Unidades de Polícia Pacificadora no Rio de Janeiro. In: VIII Jornada de alunos do PPGA-UFF, 2014, Niterói. VIII Jornada de alunos do Programa de Pós-Graduação em Antropologia UFF, 2014. v. 8.

JEUDY, Henri-Pierre. Memórias do social. Rio de Janeiro: Forense Universitária, 1990.

LATOUR, Bruno. Como falar do corpo? A dimensão normativa dos estudos sobre a ciência. Tradução de Gonçalo Praça. In: ARRISCADO, João; NUNE, Ricardo Roque (org) Objectos Impuros. Experiências em Estudo sobre a Ciência, Edições Afrontamento, Porto 37-62. Disponível em: <http://www.bruno-latour.fr/node/185>. Acesso em 12/08/2013.

MATTOS, Romulo. Remoções de favelas na cidade do Rio de Janeiro uma história do tempo presente. Revista Outubro (São Paulo), v. 21, p. 171-190, 2014.

MOUTINHO, Mário C. (1993). Sobre o conceito de museologia social. Cadernos de Sociomuseologia, Lisboa, v. 1, p.7-9, 1993.

POLLAK, Michael. Memória, esquecimento, silêncio. Estudos Históricos, Rio de Janeiro, v. 2, n. 3, 1989.

PORTILHO, Aline. Das "belezas que emanam dos jardins suspensos de Ipanema e Copacabana": políticas governamentais, demandas por memória e produção do espaço no Museu de Favela do Pavão-Pavãozinho e Cantagalo. Tese (Doutorado em História, Política e Bens Culturais). Rio de Janeiro: Programa de Pós-Graduação em História, Política e Bens Culturais. Fundação Getúlio Vargas, 2016.

RODRIGUES, Fernanda. Registros de Memória em Arte Fugaz: o Graffiti das Casas-Telas do Museu de Favela (2010-2014). Dissertação (Mestrado em Memória Social) - Programa 
de Pós-Graduação em Memória Social. Universidade Federal do Estado do Rio de Janeiro, Rio de Janeiro, 2015.

SANTOS, Milton. Por uma outra globalização: do pensamento único à consciência universal. Rio de Janeiro: Record, 2000.

SANTOS, Rita de Cássia. Becos e vielas do Museu de Favela. Cadernos do CEOM, Santa Catarina, v. 27, n.41, p. 329-332, 2014.

TOLENTINO, Atila. Museologia Social: apontamentos históricos e conceituais. Cadernos de Sociomuseologia, Lisboa, v. 52, p. 21-44, 2016.

UNESCO. ICOM. Documento da Mesa Redonda de Santiago do Chile. Santiago, 1972

UNESCO. ICOM. Declaração de Quebec. Quebec, 1984.

\section{Leonardo Perdigão Leite}

Mestre e doutorando em Psicologia Social pelo PPGPS/UERJ. Museólogo e Pedagogo. Bolsista FAPERJ 10. Também é integrante do Laboratório afeTAR.

Recebido em 17/01/2019

Aceito para publicação em 19/06/2019 